\title{
Total Enteral Nutrition Facilitates Wound Healing Through Preventing Intestinal Atrophy, Keeping Protein Anabolism and Suppressing Inflammation
}

\author{
Yutaka Suzuki $^{\mathrm{a}, \mathrm{c}}$, Naruo Kawasaki ${ }^{\mathrm{a}}$, Mitsuyoshi Urashima ${ }^{\mathrm{b}}$, Hironori Odaira ${ }^{\mathrm{a}}$, Takuji Noro ${ }^{\mathrm{a}}$
}

\begin{abstract}
Background: In clinical settings, early total enteral nutrition (TEN) is known to reduce the postoperative complication and infection rate as well as duration of postoperative stay compared with total parenteral nutrition (TPN) in a variety of critical conditions. We aimed to compare effects TEN and TPN on wound healing and explore its possible mechanisms using rat model.
\end{abstract}

Methods: Seven days after operation for inserting enteral tube into gastric space for TEN, Sprague-Dawley rats were made burn (15 $\mathrm{mm})$ in the back. Rats were administrated with either TEN ( $\mathrm{N}=$ 17) or TPN $(\mathrm{N}=15)$ and evaluated condition of wound healing as well as serum/urine immunological and biochemical parameters at 28 days.

Results: Burned area was significantly reduced in TEN than in TPN group. Although body weight, serum levels of total protein, albumin and transferrin were the same levels between the two groups, urine nitrogen and intestinal atrophy were significant in TPN group. Conversely, weight of small bowel showed positive linear relationship with levels of parameters calculated as follows: [medication nitrogen quantity - (urine nitrogen + feces nitrogen)]/[medication nitrogen - feces nitrogen quantity]. Weights of spleen and tumor necrotizing factor-a levels in serum were higher in TPN than in TEN.

Conclusions: These results suggest that TEN may facilitate wound healing compared with TPN through preventing intestinal atrophy,

\footnotetext{
Manuscript accepted for publication August 5, 2009

aDepartment of Surgery, International University of Health and Welfare ${ }^{\text {b} D i v i s i o n ~ o f ~ C l i n i c a l ~ R e s e a r c h ~ \& ~ D e v e l o p m e n t, ~ J i k e i ~ U n i v e r s i t y ~ S c h o o l ~}$ of Medicine

${ }^{c}$ Corresponding author: Yutaka Suzuki MD, PhD. 537-3, Iguchi,

Nasusiobara, Tochigi 329-2763, Department of Surgery, International

University of Health and Welfare. E-mail: yutaka@iuhw.ac.jp
}

keeping protein anabolism and suppressing inflammation.

Keywords: Total enteral nutrition; Total parenteral nutrition; Wound healing; Rats; Cytokine

\section{Introduction}

In clinical settings, early total enteral nutrition (TEN) is known to reduce the postoperative complication and infection rate as well as duration of postoperative stay compared with total parenteral nutrition (TPN) in a variety of critical conditions: postoperative recovery [1-3], abdominal trauma $[4,5]$, pancreatitis [6], burn [7-9]. To support the superiority of TEN to TPN obtained as clinical evidences, rodent's models demonstrated a couple of mechanisms that TEN reduced cytokine production after operation or burn [10,11], TPN increased apoptosis in the small bowel mucosa [12] and bacterial and endotoxin translocation [13-15]. However, these evidence using rodents models were fragmented and not comprehensive. Therefore, we aimed to compare effects of TEN and TPN on wound healing by measuring a variety of parameters using burned rat model.

\section{Materials and Methods}

\section{Treatment of animals}

All studies were carried out in compliance with the institutional guidelines of animal experiments at Jikei University School of Medicine. Male Sprague-Dawley rats at 11 weeks (Charles River Japan Inc., Yokohama, Japan) were fed with CRF-1: standard meal for rats (Oriental Co., Tokyo, Japan). After making sure rats' condition healthy by spending 7 days, either intragastric root for TEN or intravenous root for TPN was obtained under anesthesia induced by administrating $40 \mathrm{mg} / \mathrm{kg}$ of pentobarbital intraperitoneally. For TEN group, a polyvinyl catheter (5 Fr) (Japan Sharwood, Tokyo, Japan) was inserted into intragastric space of the rat and the other end of catheter was guided subcutaneously 
Table 1. Components of nutrients used for TEN or TPN (/100 kcal)

\begin{tabular}{|c|c|c|c|}
\hline Component & & TEN"1 & $\mathbf{T P N}^{* 2}$ \\
\hline Carbohydrate & & $14.68 \mathrm{~g}$ & $20.59 \mathrm{~g}$ \\
\hline \multirow[t]{2}{*}{ Lipid } & LCT & $0.812 \mathrm{~g}$ & $0.374 \mathrm{~g}$ \\
\hline & $\mathrm{MCT}$ & $1.968 \mathrm{~g}$ & $0 \mathrm{~g}$ \\
\hline Amino acid & & $4.05 \mathrm{~g}$ & $3.53 \mathrm{~g}$ \\
\hline Total nitrate & & $0.6 \mathrm{~g}$ & $0.55 \mathrm{~g}$ \\
\hline Volume & & $100 \mathrm{ml}$ & $120 \mathrm{ml}$ \\
\hline Calorie/N & & 176 & 182 \\
\hline Calorie of non protein & & $83.7 \mathrm{kcal}$ & $85.9 \mathrm{kcal}$ \\
\hline Calorie of non protein $/ \mathrm{N}$ & & 140 & 157 \\
\hline
\end{tabular}

to the back, and then connected with joint pipe with stainless steel by opened abdominal operation. For TPN group, opened abdominal operation alone was performed.

One week after abdominal operation, burns were made on the center of rats' back under anesthesia by intraperitoneally administrating pentobarbital. Briefly, after shaving the back, 42 rats had burn of $15 \mathrm{~mm}$ in diameter by pressing an electrical soldering iron at $200{ }^{\circ} \mathrm{C}$ for 30 seconds. Two days after making burn, debridement was performed for skin of wound tissue under anesthesia with pentobarbital. Three days after making burn, absorbent cotton covered with OpSite Wound (Smith and Nephew Inc., Florida, USA) was put on wound tissue to absorb exudative solution. Wound healing was leave opened between 7 and 28 days after making burn.

At the day of making burn (defined as day 0), either TEN or TPN was started. For TEN, the other end of joint pipe was connected to a swivel via fixing spring with polyethylene tube through harness on the back of rat. For TPN, a small skin incision was made in the inguinal region of the rat to insert a silicon catheter (inner diameter: $0.5 \mathrm{~mm}$, outer diameter: $1.0 \mathrm{~mm}$; Kaneka Medix, Tokyo, Japan) into the right femoral vein to reach vena cava inferior. The other end of the catheter was guided subcutaneously to the posterior aspect of the neck, and then connected to a swivel via harness on the back of rat. The skin wound for insertion of the catheter was closed by a stitch of 3-0 silk. Rats of TEN group had incision at inguinal region alone.

Either TEN or TPN, nutrition was continuously infused through polyethylene tube connecting to the other side of swivel for 24 hours per day using perista pump (Watoson-
Marlow 502S; Nikkisou Co. Ltd., Tokyo, Japan) without peroral feeding. Rats belonging to either TEN or TPN group were administrated nutrition $60 \mathrm{kcal} /$ day from day 0 to day 1 and $80 \mathrm{kcal} /$ day from day 2 to day 28 . To confirm normal range of parameters, control rats $(\mathrm{N}=12)$ not treated with burn or operation were fed with the same calorie during the same period of time. Components of nutrients used for TEN: Twinline ${ }^{\circledR}$ (Otsuka Pharmaceutical Co., Ltd.; Tokyo, Japan), and for TPN: Unicaliq ${ }^{\circledR}(\mathrm{N})$ (Termo Co., Tokyo, Japan) + Multamin ${ }^{\circledR}$ (Sankyo Co. Ltd., Tokyo, Japan) + Mineralin $\AA$ (Takeda Pharmaceutical Co. Ltd., Tokyo, Japan) + Intrafat ${ }^{\circledR}$ (20\%) (Takeda Pharmaceutical Co. Ltd., Tokyo, Japan) + 20\%(W/W) Choline chloride (Wako Pure Chemical Ind., Osaka, Japan), solutions were shown in Table 1. These solutions were made up in clean bench. As a control group, rats without operation nor treatment for burn were fed CRF-1 for the same calorie during the same experimental period to know normal ranges of serum/urine parameters for nutrition and inflammation.

At final day of observation, opened abdominal operation was performed under anesthesia with intraperitoneally administrated pentobarbital for blood sampling from portal vein and vena cava inferior. After sacrificed with total bleeding, spleen was resected for weight measure.

\section{Outcome measures}

Degree of wound healing was estimated by area of wound at day 0 of making burn and day 28 of sacrificed using Image analysis software (IPAP-WIN: Sumika Technoservice Co., Osaka, Japan) for measuring area. Body weights were 


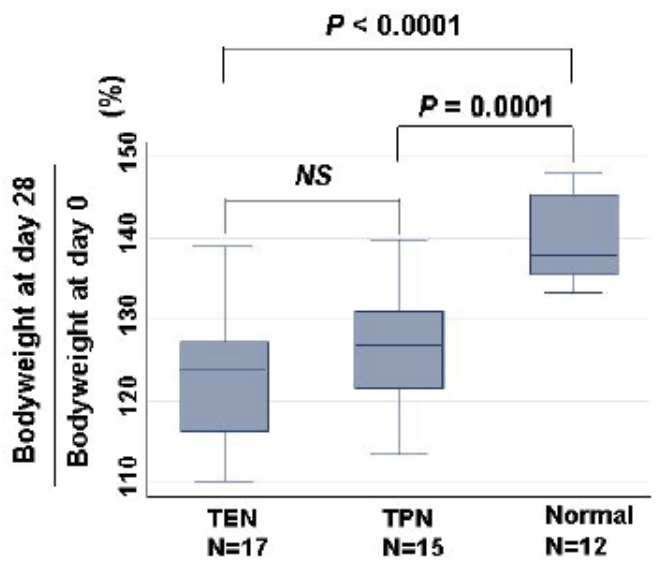

Figure 1. Comparison of bodyweight changes among TEN, TPN, and normal groups. Changes were calculated as bodyweight at day 28 / bodyweight at day 0 (\%). Statistical difference was evaluated with Man Whitney $U$ test.

measured at day 0 and day 28 .

Urine and stool were collected during day 23, day 24 and day 25. Urine was frozen and stool was freeze-dried and packaged until nitrogen measures. Urine and feces nitrogen quantity was determined daily by a chemiluminescence technique from day 0 to day 28 after burn. Nitrogen accounts $=$ medication nitrogen $-($ urine nitrogen + feces nitrogen $)$; Prices $=$ nitrogen accounts $/($ medication nitrogen - feces nitrogen)

Serum protein levels were measured as following combinations: prolyl hydroxylase by enzyme immunoas- say (EIA)-kit (Fujiyakuhin Co., Ltd. Saitama, Japan); total protein and albumin by A/G B-test WAKO (Wako Pure Chemical Ind., Osaka, Japan); transferrin by EIA-kit (Panafirm Laboratories Co. Ltd., Kumamoto, Japan); sialic acid by sialic acid measurement kit (Kyokuto Pharmaceutical Industrial Co., Ltd. Tokyo, Japan); endotoxin assay kit by toxi-color (Seikagaku Co., Tokyo, Japan); tumor necrotizing factor (TNF)- $\alpha$, interleukin (IL)-6, IL-4 and IL-10 by ELISA kit (Biosource International Inc., California, USA); IL-8 by Rat GRO/CINC ELISA system (Amersham Lifescience Inc., Buckinghamshire, UK). Biochemical parameters were measured with an automatic serum analyzer (Model 7150, Hitachi Ltd., Tokyo, Japan).

\section{Statistics}

Significant differences among TEN, TPN and control group were estimated with Kruskal-Wallis test and defined as significant when $p$-value was less than 0.05 . On the other hand, significant differences between two groups: TEN and TPN; TEN and control; TPN and control; were estimated with Mann-Whitney (Two-sample Wilcoxon rank-sum) test. The difference was defined significant when $p$-value was less than 0.016 according to Bonferroni correction. All statistical analyses were performed using STATA version 8.0 (Stata Corporation, College Station, TX, USA).

\section{Results}

\section{Changes of body weight and nutrition markers}

Table 2. Effects of TEN on nutrition

\begin{tabular}{lllll}
\hline Biomarker & $\begin{array}{l}\text { TEN } \\
\mathbf{N}=\mathbf{1 7}\end{array}$ & $\begin{array}{l}\mathbf{T P N}^{* 2} \\
\mathbf{N}=\mathbf{1 5}\end{array}$ & $\begin{array}{l}\text { Control }^{* 3} \\
\mathbf{N = 1 2}\end{array}$ & Kruskal-Wallis $^{* 1}$ \\
\hline Medication nitrogen quantity & $947.8 \pm 27.3$ & $881.2 \pm 15.1^{\ddagger}$ & $1515.7 \pm 8.1^{\ddagger}$ & 0.0001 \\
Urine inside nitrogen quantity & $659.2 \pm 63.6$ & $755.1 \pm 73.2^{\dagger}$ & $625.4 \pm 42.1^{\ddagger}$ & 0.0077 \\
Feces inside nitrogen quantity & $62.2 \pm 30.7$ & $22.9 \pm 8.6^{\dagger}$ & $365.4 \pm 7.1^{\ddagger}$ & $<0.0001$ \\
Nitrogen accounts & $226.3 \pm 87.2$ & $103.3 \pm 80.7^{\dagger}$ & $524.8 \pm 34.9^{\ddagger}$ & $<0.0001$ \\
Prices & $25.3 \pm 9.1$ & $11.9 \pm 9.3^{\dagger}$ & $45.6 \pm 3.3^{\ddagger}$ & $<0.0001$ \\
Total protein $(\mathrm{g} / \mathrm{dl})$ & $5.4 \pm 0.3$ & $5.3 \pm 0.4$ & $4.9 \pm 0.2^{\ddagger}$ & 0.0004 \\
Albumin $(\mathrm{g} / \mathrm{dl})$ & $1.8 \pm 0.1$ & $1.8 \pm 0.1$ & $2.2 \pm 0.1^{\ddagger}$ & $<0.0001$ \\
Transferrin $(\mathrm{mg} / \mathrm{ml})$ & $3.19 \pm 0.41$ & $3.13 \pm 0.62$ & $3.16 \pm 0.50^{\ddagger}$ & 0.0005 \\
\hline
\end{tabular}

*1: Statistical differences were calculated based on Kruskal-Wallis equality of populations rank test. Statistical significance was defined when p-value was less than 0.05. *2: Value of TPN was compared with TEN by correcting with Bonferroni. *3: Value of control was compared with TEN.: $† p<0.016, \ddagger$ : $p<0.005$. 


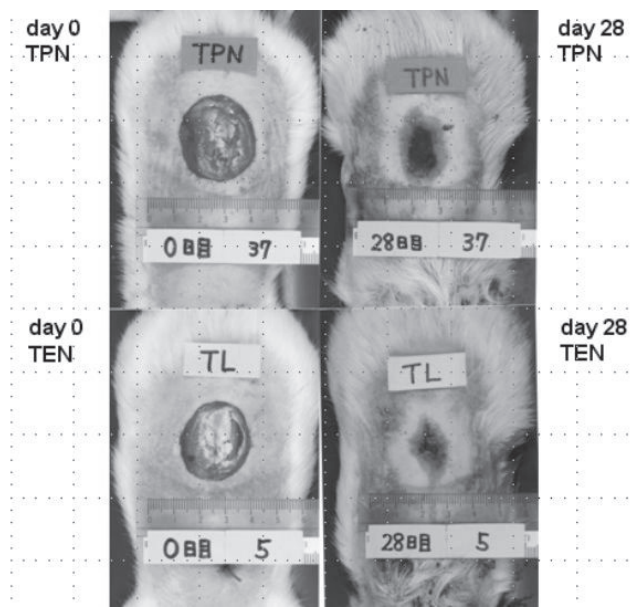

Figure 2. Difference of burned area at day 0 (left panel) and day 28 (right panel) between TPN (upper) and TEN (lower).

Total calorie intake was not different among TEN $(\mathrm{N}=17 ; 2223.0 \pm 10.0 \mathrm{kcal})$, TPN $(\mathrm{N}=15 ; 2246.1 \pm 11.0 \mathrm{kcal})$ and control groups $(\mathrm{N}=12 ; 2203.7 \pm 12.0 \mathrm{kcal})$. Percent changes of body weight at day 28 divided by bodyweight at day 0 were compared among TEN, TPN, and normal groups (Fig. 1). Increase of body weight was equivalent between TEN $(\mathrm{N}=17 ; 122.4 \pm 7.8 \%)$ and TPN $(\mathrm{N}=15 ; 126.3 \pm 7.2 \%)$. While body weights of burned rats treated with either TEN or TPN were significantly less than control rats without burn $(\mathrm{N}=12 ; 139.8 \pm 5.1 \%)$.

Nutritional markers were compared among three groups (Table 2). Although medication nitrogen quantity and feces nitrogen was least in TPN group, urine nitrogen was most. Thus, the prices were least in TPN, second in TEN, and most in control group. Serum levels of total protein, albumin and transferrin at day 28 were equivalent between TEN and TPN, whereas those of control group were significantly higher than TEN and TPN.

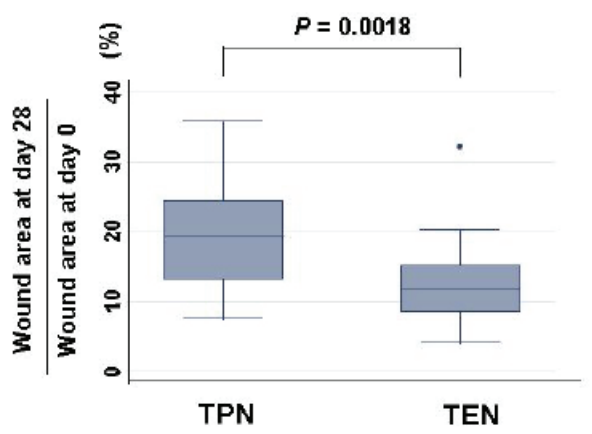

Figure 3. Changes of burned area: burned area at day 28 divided by wound area at day $0(\%)$ in either TPN or TEN. Statistical difference was evaluated with Man Whitney $U$ test.

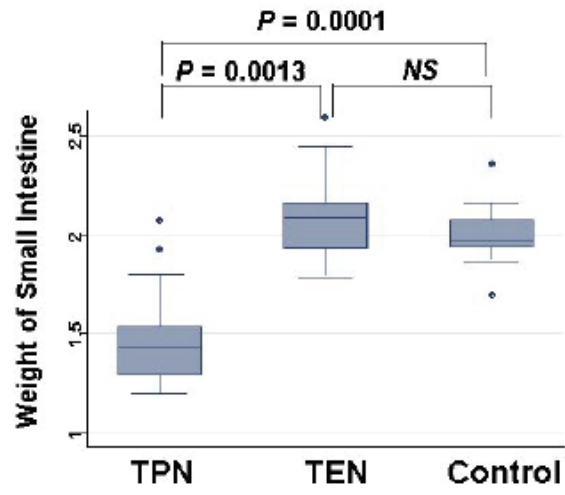

Figure 4. Comparison of weights of small intestine at day 28 among TPN, EN and control group. Statistical difference was evaluated with Man Whitney U test.

\section{Effects of TEN on wound healing}

Typical wound areas of rats' back at day 28 treated with either TEN or TPN were shown as Figure 2. Burned area was significantly smaller in rats treated with TEN $(12.7 \pm 1.6 \%$ of burned area at day 0$)$ than with TPN $(19.0 \pm 2.3 \%$ of burned area at day 0) (Fig. 3). Serum levels of prolyl hydroxylase were significantly lower in TEN $(449.4 \pm 98.2 \mathrm{ng} / \mathrm{ml})$ than TPN group $(953.2 \pm 611.3 \mathrm{ng} / \mathrm{ml})(\mathrm{P}=0.0004)$, which were more than control $(286.5 \pm 41.3 \mathrm{ng} / \mathrm{ml})(\mathrm{P}=0.0001)$.

\section{Effects of TEN on morphology of small intestine}

Weight of small intestinal loop per $100 \mathrm{~g}$ of body weight was heavier in TEN $(2.08 \pm 0.22 \mathrm{~g})$ and control group $(2.00 \pm 0.16 \mathrm{~g})$ than in TPN group $(1.48 \pm 0.26 \mathrm{~g})$, although no significant difference existed between TEN and control group (Fig. 4). Then, length of villi and depth of crypt were

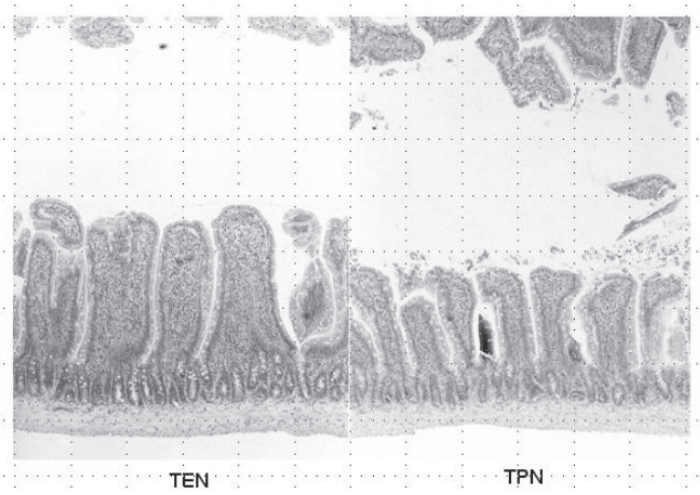

Figure 5. Hematoxylin and eosin staining of jejunum obtained from TEN (left panel) and TPN (right panel). 


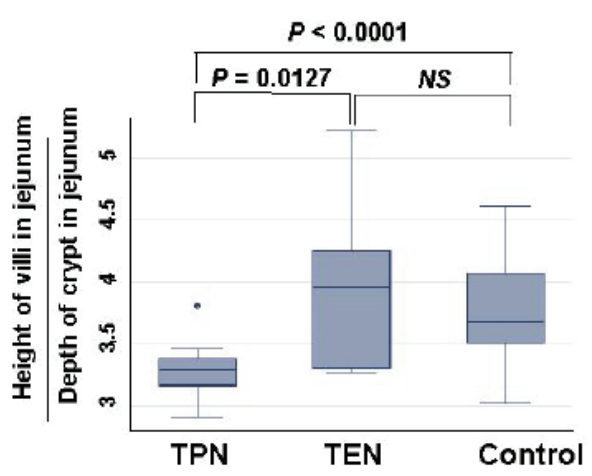

Figure 6. Comparison of ratio: length of villi divided by depth of crypt in jejunum among TPN, EN and control group. Statistical difference was evaluated with Man Whitney $U$ test.

measured in duodenum, jejunum and ileum under hematoxylin eosin staining among TEN, TPN, and control group: Examples of hematoxylin and eosin staining of jejunum were shown (Fig. 5). Then, ratio: length of villi divided by depth of crypt in jejunum was compared among TPN, TEN and control group (Fig. 6). The ratio was significantly smaller in TPN group than in TEN $(\mathrm{P}=0.012)$. Weight of small bowel per $100 \mathrm{~g}$ of bodyweight showed positive and linear association with anabolism of nitrogen (Fig. 7).

\section{Effects of TEN on immunological and biochemical mark-} ers

Other parameters possibly related with wound healing were also compared among TEN, TPN, and control group (Table 3). Among cytokines measured in this experiment, only TNF- $\alpha(\mathrm{P}=0.0042)$ were significantly higher in TPN group than in TEN. Weights of spleen were also heavier in TPN than in TEN $(\mathrm{P}<0.0001)$ or control group $(\mathrm{P}<0.0001)$.

Both serum levels of direct $(\mathrm{P}=0.0025)$, indirect bilirubin $(\mathrm{P}=0.0041)$ and alkaliphosphatase $(\mathrm{P}=0.0083)$ were

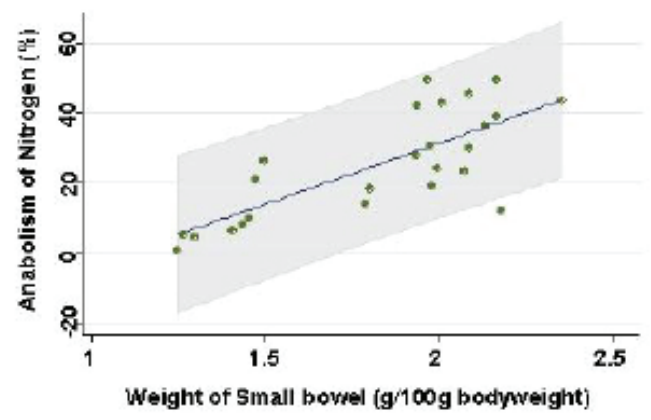

Figure 7. Association between weight of small bowel and prices. Line and gray area are showing linear regression and 95\% confidence interval, respectively. significantly higher in TPN group than in TEN group. Moreover, BUN $(\mathrm{P}=0.0058)$ and creatinine $(\mathrm{P}=0.0021)$ were also higher in TPN group than in TEN group. In contrast, plasma glucose $(\mathrm{P}=0.0015)$ and triglyceride levels $(\mathrm{P}=$ 0.0001 ) were lower in TPN group than in TEN group.

\section{Discussion}

In this study, wound healing was faster in TEN group than in TPN group, in spite of equivalent body weight changes after burn. There were few original articles to demonstrate superiority of TEN to TPN in wound healing using rat model [16-18]. Judging from data of nitrogen accounts and prices in this experiment, TEN can direct more anabolic state than TPN, although total protein, albumin, transferrin were equivalent between TPN and TEN group. In addition, blood urea nitrogen (BUN) that is one of protein metabolites was lower in TEN than in TPN in our study. TPN treated malnourished rats gained more weight with greater body fat formation than TEN group but had lower nitrogen [19]. Thus, our results and a previous report suggest that TEN may facilitate wound healing by maintaining protein anabolism more than TPN.

Weight of small intestinal loop was heavier in TEN and control group than in TPN group, although no significant difference existed between TEN and control group. Moreover, ratio length of villi divided by depth of crypt was significantly smaller in TPN group than in TEN and control group, which may be consistent with previous reports that morphometry revealed an increased submucosal thickness while intestinal circumference markedly decreased in TPNtreated rats compared with TEN [20, 21]. TPN may keep gut little stress, conversely cause mucosal atrophy. Furthermore, these morphological changes induced by TPN were demonstrated to associate with reduced lymphocytes, increased gut permeability and enhanced bacterial translocation [22-26], which can increase risk of postoperative sepsis and postoperative morbidity/mortality [13, 27]. Small intestinal atrophy was shown to affect nitrogen metabolism to a greater extent than liver by-pass [28], which was also reconfirmed in our study that weight of small bowel showed positive linear relationship with levels of nitrate anabolism.

Among cytokine production, serum levels of TNF- $\alpha$ were significantly lower in TEN than in TPN group. TPN increases the expression of TNF- $\alpha$ mRNA in organ tissues and systemic TNF- $\alpha$ production, and reduces the survival rate of rats after thermal injury, but TEN does not [11]. Thus, differences in cytokine levels between TEN and TPN in our study were consistent with previous studies. Moreover, increased weight of spleen confirmed in this study was not pointed out previously to our knowledge. Decreased stimulation to intestinal immunity may be compensated by hypertrophy of spleen at least in part.

Serum levels of bilirubin and alkaliphosphatase were 
Table 3. Effects of TEN on inflammation

\begin{tabular}{|c|c|c|c|c|c|}
\hline Types & Biomarker & $\begin{array}{l}\text { TEN } \\
\mathbf{N}=17\end{array}$ & $\begin{array}{l}\text { TPN } \\
N=15\end{array}$ & $\begin{array}{l}\text { Control } \\
\mathrm{N}=12\end{array}$ & Kruskal-Wallis *1 \\
\hline \multirow[t]{8}{*}{ Immune } & Sialic acid (mg/dl) & $109.6 \pm 12.2$ & $125.5 \pm 21.5$ & $75.6 \pm 6.8^{\ddagger}$ & $<0.0001$ \\
\hline & IL-4 (pg/ml) & $5.4 \pm 8.3$ & $10.6 \pm 12.7$ & $9.7 \pm 10.6$ & NS \\
\hline & IL-6 (pg/ml) & $2.4 \pm 6.7$ & $56.7 \pm 91.6$ & $0 \pm 0$ & 0.0061 \\
\hline & IL-8 (pg/ml) & $193.2 \pm 144.0$ & $283.5 \pm 277.0$ & $122.8 \pm 46.4$ & NS \\
\hline & $\mathrm{IL}-10(\mathrm{pg} / \mathrm{ml})$ & $3.6 \pm 9.8$ & $18.2 \pm 42.4$ & $3.9 \pm 13.4$ & NS \\
\hline & $\mathrm{TNF}-\alpha(\mathrm{pg} / \mathrm{ml})$ & $1.7 \pm 4.2$ & $3.9 \pm 4.1^{\ddagger}$ & $1.3 \pm 1.7$ & 0.0087 \\
\hline & Endotoxin (pg/ml) & $18.5 \pm 6.2$ & $20.1 \pm 6.1$ & $5.7 \pm 1.5$ & 0.0012 \\
\hline & Spleen (g/100g bodyweight) & $0.25 \pm 0.03$ & $0.71 \pm 0.40^{\ddagger}$ & $0.22 \pm 0.03$ & $<0.0001$ \\
\hline \multirow[t]{6}{*}{ Liver } & AST (U/l) & $129.0 \pm 42.1$ & $567.5 \pm 1005.2^{* 2}$ & $327.0 \pm 698.6$ & NS \\
\hline & $\operatorname{ALT}(\mathrm{U} / \mathrm{l})$ & $36.4 \pm 9.4$ & $92.1 \pm 145.6$ & $30.7 \pm 7.5$ & NS \\
\hline & Alkaliphosphatase (U/l) & $360.5 \pm 74.4$ & $569.1 \pm 222.8^{\ddagger}$ & $491 \pm 109.4$ & 0.0012 \\
\hline & LAP (IU/l) & $54.6 \pm 1.5$ & $70.1 \pm 25.5$ & $71.6 \pm 6.1^{\dagger}$ & 0.0066 \\
\hline & Direct bilirubin (mg/dl) & $0.113 \pm 0.057$ & $0.196 \pm 0.117^{\ddagger}$ & $0.088 \pm 0.016$ & 0.0018 \\
\hline & Indirect bilirubin (mg/dl) & $0.015 \pm 0.014$ & $0.055 \pm 0.075^{\dagger}$ & $0.030 \pm 0.012$ & NS \\
\hline \multirow[t]{2}{*}{ Renal } & BUN (mg/dl) & $18.5 \pm 2.3$ & $22.7 \pm 4.5^{*}$ & $16.4 \pm 15.5$ & $<0.0001$ \\
\hline & $\mathrm{Cr}(\mathrm{mg} / \mathrm{dl})$ & $0.46 \pm 0.05$ & $0.55 \pm 0.08^{\ddagger}$ & $0.42 \pm 0.05$ & $<0.0001$ \\
\hline \multirow[t]{3}{*}{ Metabolism } & Glucose (mg/dl) & $157.3 \pm 5.5$ & $116.8 \pm 32.7^{*}$ & $141.9 \pm 17.5$ & 0.0004 \\
\hline & Triglyceride (mg/dl) & $51.8 \pm 19.6$ & $23.1 \pm 11.1^{*}$ & $35.8 \pm 17.3^{\dagger}$ & 0.0002 \\
\hline & Total cholesterol (mg/dl) & $60.8 \pm 11.5$ & $55.5 \pm 10.4$ & $54.0 \pm 10.8$ & NS \\
\hline
\end{tabular}

*1: Statistical differences were calculated based on Kruskal-Wallis equality of populations rank test. Statistical significance was defined when $p$-value was less than 0.05 . ${ }^{*}$. Two high levels of AST $(2864,2994)$ were included in TPN group. $\dagger: p<0.016, \ddagger: p<0.005$.

significantly higher in TPN group than in TEN group. During TPN, hepatic concentration of the important intracellular antioxidant glutathione was reported to decrease [29]. Capacity of hepatic drug metabolism was shown to decrease in rats treated with TPN $[30,31]$. Moreover, BUN and creatinine were also higher in TPN group than in TEN group. Rats given TEN after ischemic acute renal failure have improved renal function compared with rats given TPN [32]. These suggest that TEN may protect multiple organs against failure in critical conditions. In contrast, plasma glucose and triglyceride levels were lower in TPN group than in TEN group, of which meanings remain unknown.

In conclusion, TEN may facilitate wound healing compared with TPN through preventing intestinal atrophy, keeping protein anabolism and suppressing inflammation.

\section{Acknowledgements}

This study was supported by Grant in Aid for Scientific Research in Japan. 


\section{References}

1. Bozzetti F, Braga M, Gianotti L, Gavazzi C, Mariani L. Postoperative enteral versus parenteral nutrition in malnourished patients with gastrointestinal cancer: a randomised multicentre trial. Lancet 2001;358(9292):14871492.

2. Wicks C, Somasundaram S, Bjarnason I, Menzies IS, Routley D, Potter D, Tan KC, et al. Comparison of enteral feeding and total parenteral nutrition after liver transplantation. Lancet 1994;344(8926):837-840.

3. Carr CS, Ling KD, Boulos P, Singer M. Randomised trial of safety and efficacy of immediate postoperative enteral feeding in patients undergoing gastrointestinal resection. BMJ 1996;312(7035):869-871.

4. Kudsk KA, Croce MA, Fabian TC, Minard G, Tolley EA, Poret HA, Kuhl MR, et al. Enteral versus parenteral feeding. Effects on septic morbidity after blunt and penetrating abdominal trauma. Ann Surg 1992;215(5):503511; discussion 511-503.

5. Moore EE, Jones TN. Benefits of immediate jejunostomy feeding after major abdominal trauma--a prospective, randomized study. J Trauma 1986;26(10):874-881.

6. Marik PE, Zaloga GP. Meta-analysis of parenteral nutrition versus enteral nutrition in patients with acute pancreatitis. BMJ 2004;328(7453):1407.

7. Ziegler TR, Smith RJ, O’Dwyer ST, Demling RH, Wilmore DW. Increased intestinal permeability associated with infection in burn patients. Arch Surg 1988;123(11):1313-1319.

8. Chiarelli A, Enzi G, Casadei A, Baggio B, Valerio A, Mazzoleni F. Very early nutrition supplementation in burned patients. Am J Clin Nutr 1990;51(6):1035-1039.

9. Gudaviciene D, Rimdeika R, Adamonis K. Nutrition of burned patients. Medicina (Kaunas) 2004;40(1):1-8.

10. Sanderson IR, Croft NM. The anti-inflammatory effects of enteral nutrition. JPEN J Parenter Enteral Nutr 2005;29(4 Suppl):S134-138; discussion S138-140, S184-138.

11. Cui XL, Iwasa M, Kuge H, Sasaguri S, Ogoshi S. Route of feeding influences the production and expression of tumor necrosis factor alpha in burned rats. Surg Today 2001;31(7):615-625.

12. Jeschke MG, Debroy MA, Wolf SE, Rajaraman S, Thompson JC. Burn and starvation increase programmed cell death in small bowel epithelial cells. Dig Dis Sci 2000;45(2):415-420.

13. Sakamoto K, Hirose H, Ezaki T, Kawamura Y, Onizuka A, Hayashi M, Yamada T, et al. Translocation of Salmonella typhimurium in rats; effect of enteral and parenteral nutrition. Eur J Surg 2000;166(10):814-817.

14. Kotani J, Usami M, Nomura H, Iso A, Kasahara H, Kuroda Y, Oyanagi H, et al. Enteral nutrition prevents bacterial translocation but does not improve survival during acute pancreatitis. Arch Surg 1999;134(3):287-292.

15. Kiyama T, Efron DT, Tantry U, Barbul A. Effect of nutritional route on colonic anastomotic healing in the rat. J Gastrointest Surg 1999;3(4):441-446.

16. Kitamura Y, Tanigawa T, Katsumoto T, Tomita K, Wang HR, Hirai K, Ichihara K, et al. Cell growth and differentiation of a novel mouse Ito (fat-storing) cell line transformed by a temperature-sensitive mutant of simian virus 40. Hepatology 1997;26(2):323-329.

17. Kiyama T, Efron DT, Tantry U, Barbul A. Trauma and wound healing: role of the route of nutritional support. Int J Surg Investig 2001;2(6):483-489.

18. Kiyama T, Witte MB, Thornton FJ, Barbul A. The route of nutrition support affects the early phase of wound healing. JPEN J Parenter Enteral Nutr 1998;22(5):276279.

19. Kudsk KA, Stone JM, Carpenter G, Sheldon GF. Effects of enteral and parenteral feeding of malnourished rats on body composition. J Trauma 1982;22(11):904-906.

20. Ekelund M, Qader SS, Hallen M, Ekblad E. Effects of total parenteral nutrition on rat enteric nervous system, intestinal morphology, and motility. J Surg Res 2005;124(2):187-193.

21. Ekanger R, Vintermyr OK, Houge G, Sand TE, Scott JD, Krebs EG, Eikhom TS, et al. The expression of cAMP-dependent protein kinase subunits is differentially regulated during liver regeneration. J Biol Chem 1989;264(8):4374-4382.

22. Ruiz-Santana S, Lopez A, Torres S, Rey A, Losada A, Latasa L, Manzano JL, et al. Prevention of dexamethasone-induced lymphocytic apoptosis in the intestine and in Peyer patches by enteral nutrition. JPEN J Parenter Enteral Nutr 2001;25(6):338-345.

23. Wildhaber BE, Yang H, Spencer AU, Drongowski RA, Teitelbaum DH. Lack of enteral nutrition--effects on the intestinal immune system. J Surg Res 2005;123(1):8-16.

24. Ohta K, Omura K, Hirano K, Kanehira E, Ishikawa N, Kato Y, Kawakami K, et al. The effects of an additive small amount of a low residual diet against total parenteral nutrition-induced gut mucosal barrier. Am J Surg 2003;185(1):79-85.

25. Shou J, Lappin J, Minnard EA, Daly JM. Total parenteral nutrition, bacterial translocation, and host immune function. Am J Surg 1994;167(1):145-150.

26. Purandare S, Offenbartl K, Westrom B, Bengmark S. Increased gut permeability to fluorescein isothiocyanatedextran after total parenteral nutrition in the rat. Scand J Gastroenterol 1989;24(6):678-682.

27. Zaloga GP, Roberts P, Black KW, Prielipp R. Gut bacterial translocation/dissemination explains the increased mortality produced by parenteral nutrition following methotrexate. Circ Shock 1993;39(4):263-268.

28. Bertolo RF, Chen CZ, Pencharz PB, Ball RO. Intestinal atrophy has a greater impact on nitrogen metabo- 
lism than liver by-pass in piglets fed identical diets via gastric, central venous or portal venous routes. J Nutr 1999;129(5):1045-1052.

29. Dzakovic A, Kaviani A, Eshach-Adiv O, Perez-Atayde A, Ling PR, Yu M, Bistrian B, et al. Trophic enteral nutrition increases hepatic glutathione and protects against peroxidative damage after exposure to endotoxin. J Pediatr Surg 2003;38(6):844-847.

30. Knodell RG, Steele NM, Cerra FB, Gross JB, Solomon TE. Effects of parenteral and enteral hyperalimentation on hepatic drug metabolism in the rat. J Pharmacol Exp Ther 1984;229(2):589-597.

31. Knodell RG, Spector MH, Brooks DA, Keller FX, Kyner WT. Alterations in pentobarbital pharmacokinetics in response to parenteral and enteral alimentation in the rat. Gastroenterology 1980;79(6):1211-1216.

32. Mouser JF, Hak EB, Kuhl DA, Dickerson RN, Gaber LW, Hak LJ. Recovery from ischemic acute renal failure is improved with enteral compared with parenteral nutrition. Crit Care Med 1997;25(10):1748-1754. 